\title{
PROCEEDINGS
}

\section{SPORTS FITNESS AND ITS RELATIONSHIP TO SPORTS INJURIES}

\author{
Proceedings of a One Day Seminar at Liverpool Polytechnic, \\ organised by the Physical Education Department of Liverpool Polytechnic \\ and the Association of Chartered Physiotherapists in Sports Medicine, \\ on May 15th 1976
}

\section{CHAIRMAN'S INTRODUCTION:*}

\author{
Surgeon Rear Admiral S. MILES, C.B., M.Sc., M.D., F.R.C.P., F.R.C.S. \\ Postgraduate Dean, Faculty of Medicine, University of Manchester
}

I want first to put forward a definition of health which covers most of the associated problems.
“HEALTH IS THE ABILITY OF THE INDIVIDUAL TO MOBILISE HIS RESOURCES, PHYSICALLY, MENTALLY AND SPIRITUALLY FOR THE PRESERVATION AND ADVANTAGE OF HIMSELF, HIS DEPENDENTS AND THE SOCIETY TO WHICH HE BELONGS".

The word "mobilise" brings in the positive side of health. "Resources" vary from one person to another and ever people with gross physical deformities can achieve a great deal and live a very healthy and productive life. The use of the terms "physically, mentally, spiritually" is preferable to the alternative in the World Health Organisation's definition, i.e. "physically, psychologically and socially". "Preservation" implies survival. Positive health is concernec高 with health and survival plus, so I introduce in my definition the word "advantage" which covers the productive side $\frac{0}{D}$ We are chiefly concerned for ourselves rather than anybody else but we must consider others and so put our dependent $\Omega$ second and everybody else third. This definition is presented to provide a working base for the different specialists with $\overrightarrow{\vec{B}}$ a common interest in health.

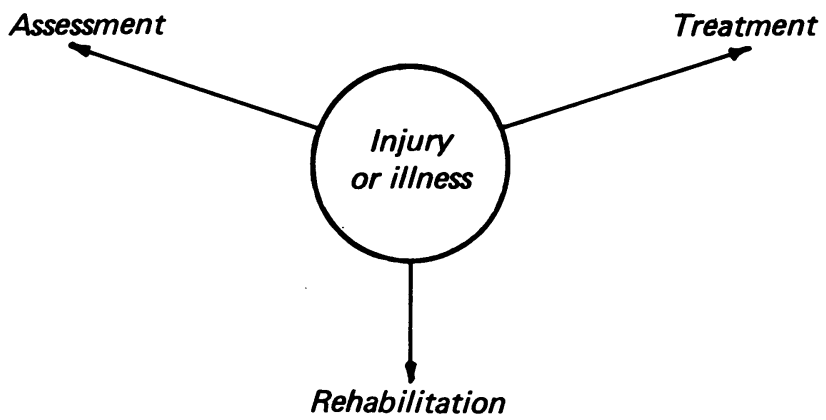

Fig. 1 The Management of Injury

I can now proceed to discuss the problem of injuries. The management of injury is illustrated diagrammatically im Fig. 1. When confronted with an injury the important thing is the assessment of that injury. "Diagnosis" is a dying word and is out of date in that so far as medicine is concerned diagnosis is a funnel through which all available information is channelled before broadening out into a wide spectrum of treatment which is looked up in a book andए applied. "Assessment" embraces every system and requires treatment of the individual as a whole. It is not the injuris that is treated but the person. Assessment, treatment and rehabilitation are all equally important and should start as soon as possible. An admirable feature of the techniques of sports medicine is that rehabilitation often begins before the treatment. Rehabilitation is after all no more than a continuation of prevention.

*Present address - Gaelic Healthguard Co. Ltd., Aberdeen. 
From a research point of view, once injury occurs, the causes of that injury - personal involvement, environmental के factors and chance - should be studied. Chance can be the one thing that makes life worth living. It is the root of all 3 biological and physical evolution, the chance impacts of atomic and subatomic particles, the chance meeting of human $\stackrel{D}{2}$ beings, the chance of fertilisation in reproduction and the chance of injury. In any one week each of us has about a 1 in $\ddot{\vec{\Rightarrow}}$ $\mathbf{8 0 0 0}$ chance of being injured. It is still 8000 to 1 against for the following week, so that there is no immunity as far as $\stackrel{0}{9}$ chance is concerned.

$$
\text { IIIness or Injury }=\text { Chance } \times \text { Environment } \times \frac{\text { Accident Proneness }+ \text { Risk Acceptance }+ \text { Personal Factors }}{\text { Training }+ \text { Maturity }+ \text { Safety Measures }}
$$

\title{
Fig. 2. The accident or illness equation
}

This is an equation that I have been using for many years as a means of studying sudden illness or injury. It can be applied to the sports situation. Chance is of course the basis of a lot of sporting activities. The environment often is controlled or chosen by the individual for his own activity. It can be natural or man-made. The natural environment includes other people and animals in its make-up. These can produce hazards as far as the individual is concerned. The man-made environment is of course one of the big headaches of today.

The accident prone people persistently have minor accidents and minor illnesses. There is invariably a psychological reason for this, such as unhappy homes or broken marriages, frustrated living or dissatisfaction with conditions of life in general. This is really a psychological illness, well known in the sports field.

The acceptance of risk is fairly general and most people will take risks for fun, fame or fortune. It plays a very important part in the causation of injury. The people who take bigger risks in perhaps the more dangerous sports, motor-cycling or deep-sea diving for example, have a greater reward for a greater risk. This is a fair way of living.

The fatigue factors are as suggested the minor ailments - distress, hangover, drugs, alcoholism itself, hunger. It is easy to extend the list. It is important on the day to become aware of these and prevent individuals from performing their activities if they are under the weather from one of these recognisable conditions. In the underwater world for example the common cold can be disastrous, pressure changes under water can rapidly transform this to roaring pneumonia.

Training goes without saying, it is the bread and butter of the sportsman. The same applies to maturity, which can be equated roughly with morale and motivation and plays a very important part in maintaining and improving health. Safety precautions exist to protect those under training, as well as the young and the elderly. Care is needed to ensure that the safety precautions, the padding and protective devices, do not interfere with enjoyment and productivity. It's quite wrong to introduce a lot of safety precautions in circumstances when really people should be trained to live with a dangerous environment.

With regard to the incident itself, one wants to know a little about it. I think most of us would like to eliminate al the conditions which are predisposing to injury, and we could. We could make the environment perfect, we could sort out the other causal factors, but we would always be left with the chance factor and we would be very much lost without it.

\section{FITNESS WITHIN SPORT}

\author{
V. THOMAS, D.L.C., Ph.D., \\ Physical Education Department, Liverpool Polytechnic
}

Physiotherapists are becoming increasingly aware of the specific and specialised problems posed by sports injuries. The existence of an Association of Chartered Physiotherapists in Sports Medicine is evidence of the specialised nature of this branch of physiotherapy. Often physiotherapists are unable to achieve optimal results with their athletic patients because they lack understanding of the environment within which the sportsman functions. This seminar has been organised with the aim of familiarising delegates with some aspects of this environment. 